\title{
Urinary excretion of calcium and magnesium in children
}

\author{
S. GHAZALI and T. M. BARRATT \\ From the Departments of Paediatric Surgery and Immunology, Institute of Child Health, London
}

\begin{abstract}
Ghazali, S., and Barratt, T. M. (1974). Archives of Disease in Childhood, 49, 97. Urinary excretion of calcium and magnesium in children. Urine calcium excretion in healthy children was $2 \cdot 38 \pm 0.66(\mathrm{SD} ;$ no. $=52) \mathrm{mg} / \mathrm{kg}$ per $24 \mathrm{hr}$ and urinary magnesium excretion was $2 \cdot 82 \pm 0 \cdot 79(S D ;$ no. $=23)$. The 24-hour urine calcium excretion could be predicted with reasonable confidence from the calcium/ creatinine concentration ratio of the second urine specimen passed in the morning. In this specimen the urine calcium/creatinine concentration ratio was $0 \cdot 14 \pm 0.06$ (SD; no. $=60) \mathrm{mg} / \mathrm{mg}$ and the magnesium/creatinine concentration ratio was $0 \cdot 21 \pm 0 \cdot 10$ $(\mathrm{SD}$; no. $=29) \mathrm{mg} / \mathrm{mg}$.

The upper limit of the urine calcium excretion is taken to be $4 \mathrm{mg} / \mathrm{kg}$ per $24 \mathrm{hr}$ and that of the calcium/creatinine concentration ratio in the second morning urine is 0.25 $\mathrm{mg} / \mathrm{mg}$. After a milk load of $700 \mathrm{ml} / 1 \cdot 73 \mathrm{~m}^{2}$ the urinary calcium/creatinine concentration ratio rose in the first two hours, but in no sample exceeded $0.25 \mathrm{mg} / \mathrm{mg}$.
\end{abstract}

During a study of children with urolithiasis (Ghazali, Barratt, and Williams, 1973), we detected several individuals with apparent hypercalciuria. We were dissatsified, however, with the available data on calcium excretion in healthy children in England and expressed the view that data collected on children in other countries or in other decades were not satisfactory, because, for example, habits of diet and prescription of vitamin D vary. We therefore decided to measure the urinary excretion of calcium and magnesium in healthy children.

The collection of 24-hour urine samples from children is notoriously prone to error. We have therefore also examined the use of the calcium/ creatinine concentration ratio of random urine samples, as first suggested by Nordin (1959). As it also seemed possible to us that the parameter of calcium excretion relevant to the genesis of urinary calculi was not the total 24-hour excretion but rather the peak calcium excretion after an oral calcium load, we measured the calciuretic response to a standardized intake of milk.

\section{Patients and methods}

Urine collections were obtained 24-hourly from 54 apparently healthy children aged 1 to 15 years. 13 children were at home; in the remainder the urine was

Received 27 July 1973. collected during the first 24 hours of admission to hospital for elective minor operation. The children were fed a normal diet and their activity was not restricted. In 15 of these children, aged 4 to 15 years, each voided urine specimen was collected separately for the determination of diurnal rhythm of calcium and magnesium excretion.

The second urine sample passed in the morning (designated morning urine), i.e. the first specimen voided after the overnight urine had been passed, was collected in the hydrated but fasted state. Separate morning urine specimens were obtained during the 24-hour collection from 30 of the above healthy children and from 18 postoperative children, some of whom had hypercalciuria ; morning urine specimens were also collected in a further 30 healthy children.

A standardized milk load was administered to 10 healthy children, aged 3 to 10 years, as follows. After the overnight urine had been voided, water $700 \mathrm{ml} / 1 \cdot 73 \mathrm{~m}^{2}$ was given to initiate diuresis, and two urine specimens were collected. $700 \mathrm{ml} / 1 \cdot 73 \mathrm{~m}^{2}$ cow's milk was then consumed over a 30-minute period, and urine was collected over the next 4 hours with hourly voiding whenever possible. $700 \mathrm{ml}$ cow's milk contains about $840 \mathrm{mg}$ calcium and about $32 \mathrm{~g}$ lactose.

Urine was collected with thiomersalyl $1: 10,000$ preservative. Aliquots for creatinine were centrifuged and deep frozen until assayed by an automated alkaline picrate method (Technicon Autoanalyser Methodology N-IIb). Aliquots for calcium and magnesium determination were diluted on the day of collection with 
$1 \%$ lanthanum chloride and analysed by atomic absorption spectrophotometry.

\section{Results}

24-Hour excretion of calcium and magnesium. The 24-hour urinary excretions of calcium and magnesium ( $\mathrm{mg} / 24 \mathrm{hr}$ ) as a function of body weight $(\mathrm{kg})$ are illustrated in Fig. 1 and 2 . Data from 2 children are considered as outliers and have been excluded from the calculations.* The

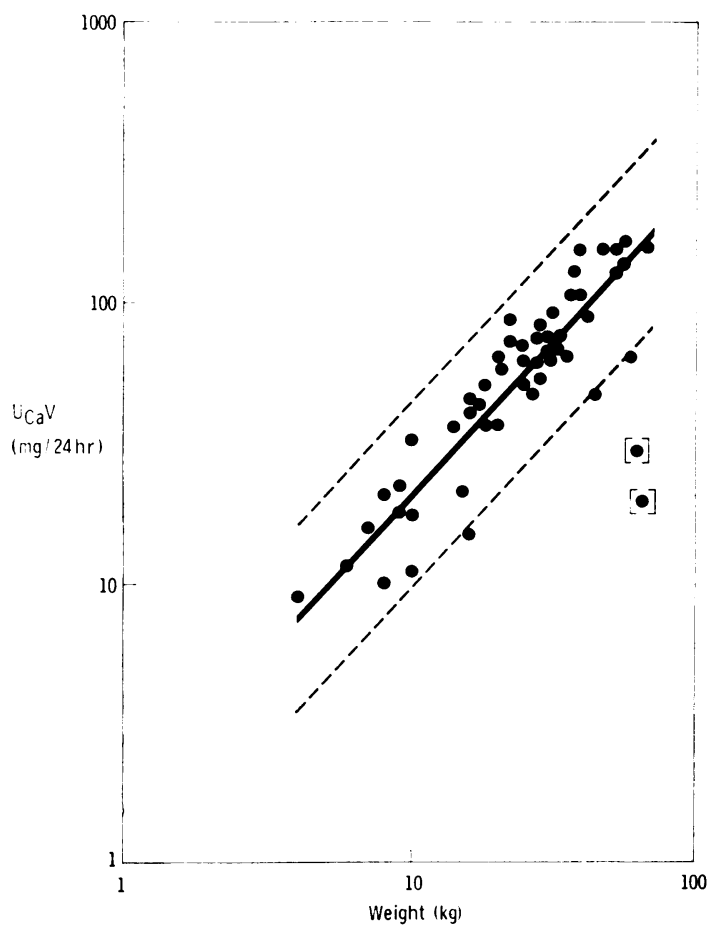

Fig. 1.-24-hour urine calcium ( $m g / 24 \mathrm{hr}$ ) plotted as a function of weight. $95 \%$ confidence limits are given. Two outliers are shown in brackets.

data have been logarithmically transformed to stabilize variances and the $95 \%$ confidence limits are shown. The equations are

$24 \mathrm{hr}$ urine calcium $=1 \cdot 8$ weight $^{1.09}$

$(r=0.91$, no. $=52)$

$24 \mathrm{hr}$ urine magnesium $=17$ weight $^{0.54}$

$(r=0 \cdot 73$, no. $=23)$.

*In 2 apparently healthy sibs urine calcium was 0.31 and 0.50 $\mathrm{mg} / \mathrm{kg}$ per $24 \mathrm{hr}$; these values are more than $4 \mathrm{SD}$ below the mean calculated for the remaining 52 children (Fig. 1). The discrepancies are not due to inadequate urine collection, for the urine creatinine excretion rates fall within the normal range. The results from these two individuals have been regarded as outliers. and have not been included in subsequent calculations.

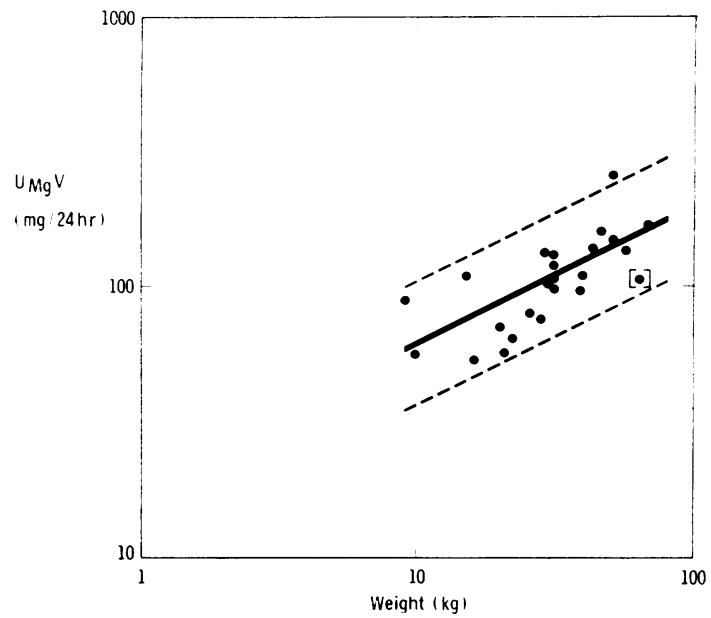

FIG. 2.-24-hour urine magnesium ( $\mathrm{mg} / 24 \mathrm{hr}$ ) plotted as a function of body weight. $95 \%$ confidence limits are given. One individual whose calcium excretion was considered to be an outlier is shown in brackets.

The slope of the regression line of the log of the 24-hour urine calcium plotted against the $\log$ of body weight (Fig. 1) does not differ significantly from unity and we have therefore related urine calcium excretion to body weight (mg/kg per $24 \mathrm{hr}$ ) in subsequent presentations. For convenience we have expressed the 24-hour magnesium excretion similarly, though it is in fact proportional to the square root of body weight.

The urine calcium excretion in 52 healthy children was $2 \cdot 38 \pm 0.66$ (SD) $\mathrm{mg} / \mathrm{kg}$ per $24 \mathrm{hr}$ (Table I). It is convenient, therefore, to consider the upper limit to be $4 \mathrm{mg} / \mathrm{kg}$ per $24 \mathrm{hr}$. There was no correlation of urine calcium with age or sex, and no difference between the children in hospital and those at home.

The urine magnesium excretion was estimated in

\section{TABLE I}

Calcium and magnesium excretion in healthy children

\begin{tabular}{|c|c|c|c|}
\hline & No. & Mean & SD \\
\hline $\begin{array}{l}\text { 24-hour urine calcium }(\mathrm{mg} / \mathrm{kg} \text { per } \\
24 \mathrm{hr}) \\
\text { Morning urine calcium } / \mathrm{creatinine} \\
\text { concentration ratio }(\mathrm{mg} / \mathrm{mg}) \\
24-h o u r \text { urine magnesium }(\mathrm{mg} / \mathrm{kg} \text { per } \\
24 \mathrm{hr}) \\
\text { Morning urine magnesium } / \mathrm{creatinine} \\
\text { concentration ratio }(\mathrm{mg} / \mathrm{mg}) \\
\text { Morning urine magnesium } / \mathrm{calcium} \\
\text { concentration ratio }(\mathrm{mg} / \mathrm{mg})\end{array}$ & $\begin{array}{l}52 \\
60 \\
23 \\
29 \\
29\end{array}$ & $\begin{array}{l}2 \cdot 38 \\
0 \cdot 14 \\
2 \cdot 82 \\
0 \cdot 21 \\
1 \cdot 6\end{array}$ & $\begin{array}{l}0.66 \\
0.06 \\
0 \cdot 79 \\
0 \cdot 10 \\
0 \cdot 7\end{array}$ \\
\hline
\end{tabular}


23 of these children, and was found to be $2 \cdot 82 \pm 0 \cdot 79$ (SD) $\mathrm{mg} / \mathrm{kg}$ per $24 \mathrm{hr}$. The concentration ratio of magnesium to calcium in these samples was $1 \cdot 3 \pm 0 \cdot 5(\mathrm{SD}) \mathrm{mg} / \mathrm{mg}$.

There was a significant positive correlation $(r=0.62, P<0.05)$ between the 24-hour urinary calcium and magnesium. However, this may in part be an artefact of urine collection errors for the correlation between the calcium/creatinine and magnesium/creatinine concentration ratios in the 24-hour urine samples did not reach significance at the $5 \%$ level $(r=0 \cdot 35)$.

Adequacy of urine collection was confirmed as far as possible by estimation of urinary creatinine excretion rate $(\mathrm{mg} / \mathrm{kg}$ per $24 \mathrm{hr}$ )

$24 \mathrm{hr}$ urine creatinine $=15 \cdot 4+0.46 \times$ age $(\mathrm{yr}) \pm$ $3 \cdot 4^{\star}(r=0 \cdot 50)$.

Urine calcium/creatinine and magnesium/ creatinine concentration ratio. The diurnal variation of the urine calcium/creatinine concentration ratio $(\mathrm{mg} / \mathrm{mg})$ is shown in Fig. 3. The ratio in each voided sample is expressed as a percentage of the measured calcium/creatinine concentration ratio of the pooled 24-hour sample, and is plotted at the midpoint of each collection period. The values obtained in the second morning urine samples showed the smallest scatter and were most representative of the 24-hour period. A similar diurnal variation of magnesium/creatinine concentration ratio was observed.

In 30 normal and 18 postoperative children the morning urine calcium/creatinine concentration

\footnotetext{
$\star$ Standard error of the estimate of $y$ from $x$.
}

ratio was estimated on a specimen obtained during the collection of the 24-hour urine. The relation between the morning calcium/creatinine concentration ratio and the 24-hour calcium excretion $(\mathrm{mg} / \mathrm{kg}$ per $24 \mathrm{hr})$ is illustrated in Fig. 4 and was found to be

$24 \mathrm{hr}$ urine calcium $=19 \cdot 4 \times$ morning calcium/ creatinine $-0 \cdot 17 \pm 1 \cdot 35^{\star}(\mathrm{r}=0 \cdot 88)$.

The morning urine calcium/creatinine concentration ratio in 60 normal children aged 1 to 15 years was $0 \cdot 14 \pm 0.06(\mathrm{SD})$; the upper limit of normal is taken to be $0.25 \mathrm{mg} / \mathrm{mg}$. There was no significant correlation with age $(r=-0.22)$ and no significant difference between the sexes.

The magnesium/creatinine concentration ratio in the morning urine in 29 of these children was $0 \cdot 21 \pm 0 \cdot 10(\mathrm{SD}) \mathrm{mg} / \mathrm{mg}$. There was a significant correlation between the calcium/creatinine and magnesium/creatinine concentration ratios in these samples $(r=0.71)$. The calcium/magnesium concentration ratio was $1 \cdot 6 \pm 0 \cdot 7(\mathrm{SD})(\mathrm{mg} / \mathrm{mg})$.

Urine calcium/creatinine concentration ratio after milk load. After the milk load, the calcium/creatinine ratio rose from 0.10 to 0.13 $\mathrm{mg} / \mathrm{mg}$ in the 2nd hour (Table II). The mean urinary calcium/creatinine concentration ratio after the milk load, expressed for each individual as a percentage of his pre-milk value, was $158 \pm 19 \%$ (SEM) in the first 3 hours after milk.

\section{Discussion}

Available data on 24-hour urinary calcium excretion in healthy children are sparse. Macy

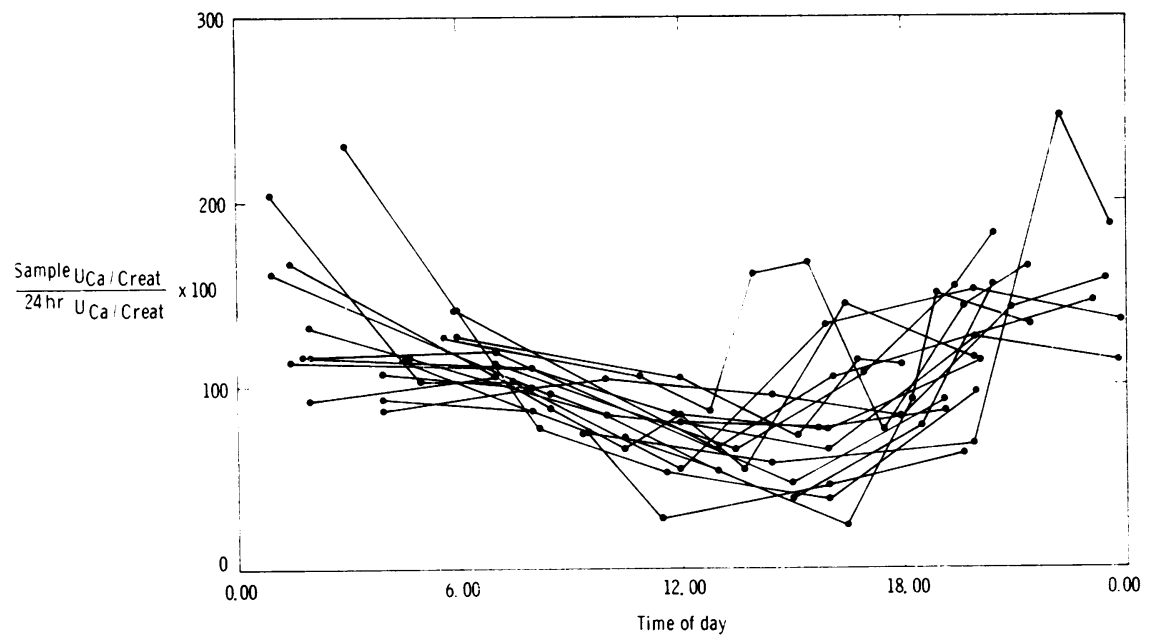

FIG. 3.-Diurnal variation of the urinary calcium/creatinine concentration ratio. 


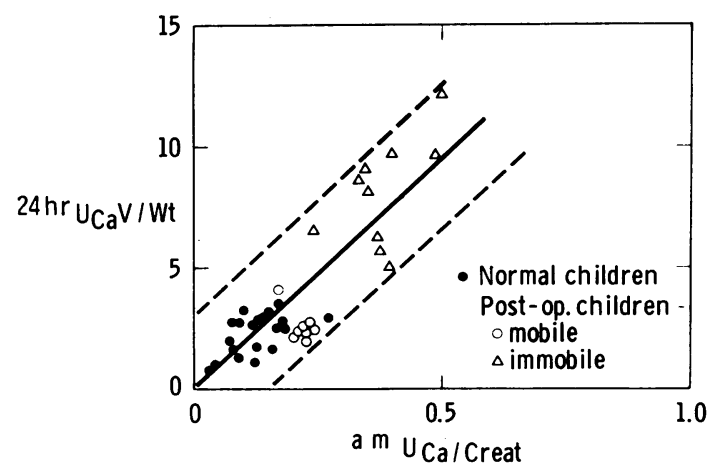

Fig. 4.-Relation between the morning (see text for definition) urine calcium/creatinine concentration ratio and the 24-hour urine calcium excretion (mg/kg per $24 \mathrm{hr}$ ).

(1946) reported the urine calcium excretion (determined by oxalate precipitation) to be $4 \cdot 7 \pm 1 \cdot 0$ $(\mathrm{SD} ;$ no. $=32) \mathrm{mg} / \mathrm{kg}$ per $24 \mathrm{hr}$ and the magnesium excretion (determined by phosphate precipitation) to be $3 \cdot 8 \pm 0.9(\mathrm{SD}$; no. $=20) \mathrm{mg} / \mathrm{kg}$ per $24 \mathrm{hr}$ in healthy American children aged 4 to 12 years. Knapp (1947) summarized the published data on urinary calcium excretion in adults and children up to 1947. On a calcium intake of $0 \cdot 7-1.0 \mathrm{~g} / 24 \mathrm{hr}$, the urine calcium excretion (determined by oxalate precipitation) in children 1 to 4 years was $47 \pm 23$; aged 5 to 9 years $79 \pm 39$; and 10 to 14 years $94 \pm 49$ (SD) $\mathrm{mg} / 24 \mathrm{hr}$. Assuming average body weights, these figures are approximately equivalent to $3 \cdot 4 \pm 1 \cdot 6,3 \cdot 4 \pm 1 \cdot 3$, and $2 \cdot 5 \pm 1 \cdot 3 \mathrm{mg} / \mathrm{kg}$ per $24 \mathrm{hr}$. Royer (1961) reported the 24-hour urine calcium excretion (oxalate precipitation) to be less than 4 $\mathrm{mg} / \mathrm{kg}$ per $24 \mathrm{hr}$ in 66 of 74 children aged 0 to 18 years, and to exceed $6 \mathrm{mg} / \mathrm{kg}$ per $24 \mathrm{hr}$ in only one. Paunier, Borgeaud, and Wyss (1970) reported the urinary excretion of calcium and magnesium

ॠRecalculated from Macy's (1946) original data using the first 24-hour urine observation in each individual. measured by atomic absorption spectrophotometry in Swiss children to be calcium $3 \cdot 6 \pm 2 \cdot 4$ (SD) $\mathrm{mg} / \mathrm{kg}$ per $24 \mathrm{hr}$ on an intake of $53 \pm 39$ (SD) $\mathrm{mg} / \mathrm{kg}$ per $24 \mathrm{hr}$, and magnesium to be $2 \cdot 8 \pm 1 \cdot 1 \mathrm{mg} / \mathrm{kg}$ per $24 \mathrm{hr}$ on an intake of $10 \cdot 5 \pm 3 \cdot 7$ (SD) $\mathrm{mg} / \mathrm{kg}$ per 24 $\mathrm{hr}$. In this series there were 38 children of whom 11 were under the age of 1 year; the infants had a significantly lower magnesium excretion and a higher (but not statistically significant) calcium excretion on a body weight standard. Excluding the infants, the urine calcium excretion in Paunier $e t$ al.'s (1970) report was $3.3 \pm 1.9 \mathrm{mg} / \mathrm{kg}$ per $24 \mathrm{hr}$ and magnesium excretion was $2 \cdot 0 \pm 1 \cdot 2$ (SD) $\mathrm{mg} / \mathrm{kg}$ per $24 \mathrm{hr}$.

In our children the urine calcium excretion at $2 \cdot 4 \pm 0 \cdot 7$ (SD) $\mathrm{mg} / \mathrm{kg}$ per $24 \mathrm{hr}$ was thus somewhat lower than the other published data, but it agrees with the figure of $2 \mathrm{mg} / \mathrm{kg}$ per $24 \mathrm{hr}$ in British children aged over 2 years estimated from the calcium/creatinine concentration ratio of random urine samples by Widdowson and McCance (1970). There are several possible explanations for these differences, of which variation in the dietary intake of sodium, calcium (Peacock, Hodgkinson, and Nordin, 1967), and vitamin $D$ are probably the most important. The dietary calcium intake was not controlled in our children, as we were concerned to determine the normal range of urine calcium excretion under the usual conditions of clinical observation.

It was convenient to find that the calcium/ creatinine concentration of the first urine specimen voided after the overnight specimen was passed was reasonably representative of the 24-hour calcium/ creatinine concentration ratio found in adults (Nordin, 1959; Dauncey and Widdowson, 1972). Assuming that the upper limit of urine calcium excretion is $4 \mathrm{mg} / \mathrm{kg}$ per $24 \mathrm{hr}$, and that the average creatinine excretion in mid-childhood is $18 \mathrm{mg} / \mathrm{kg}$ per $24 \mathrm{hr}$, the upper limit of the calcium creatinine concentration would be expected to be 0.22 ; we found that the upper limit in the morning urine

TABLE II

Calciuretic response of healthy children to an oral intake of $700 \mathrm{ml} / 1 \cdot 73 \mathrm{~m}^{2}$ cow's milk

\begin{tabular}{|c|c|c|c|c|c|c|}
\hline Hours & -2 & -1 & 1 & 2 & 3 & 4 \\
\hline $\begin{array}{l}\text { Urine calcium/creatinine } \\
\text { concentration ratio (mg/mg) } \\
\text { SD } \\
\text { \%rise above baseline } \\
\text { SEM }\end{array}$ & $\begin{array}{l}0.09 \\
0.05 \\
=\end{array}$ & $\begin{array}{c}0.10 \\
0.06 \\
= \\
\text { Milk lo }\end{array}$ & $\begin{array}{c}0 \cdot 13 \\
0.05 \\
158 \\
19 \\
\\
1 \cdot 73 \mathrm{~m}\end{array}$ & $\begin{array}{c}0 \cdot 13 \\
0.05 \\
175 \\
26\end{array}$ & $\begin{array}{c}0 \cdot 11 \\
0 \cdot 09 \\
138 \\
20\end{array}$ & $\begin{array}{r}0.09 \\
0.05 \\
113 \\
12\end{array}$ \\
\hline
\end{tabular}

Note: The $\%$ rise above baseline is significant $(P<0.05)$ in the first 3 hours after milk. However, in no specimen did the calcium creatinine concentration ratio exceed $0.25 \mathrm{mg} / \mathrm{mg}$. 
specimen in healthy children was 0.25 , which is slightly less than the upper limit in adults, suggested by Nordin (1959), of $0 \cdot 28$. This system provides a convenient screen for hypercalciuria.

Lactose is a known stimulant of calcium absorption (Wasserman, 1964), and some adult patients with recurrent calcium oxalate calculi have an exaggerated calciuretic response to oral carbohydrate (Lemann, Piering, and Lennon, 1969). It was, therefore, of interest to determine whether an oral load of milk (i.e. lactose + calcium) affected calcium excretion. The calcium/creatinine concentration ratio rose significantly above basal levels in the first 2 hours after the milk load and then returned towards the pre-milk value. These data will be used as standards against which to compare the response of stone-forming children (S. Ghazali and T. M. Barratt, in preparation).

We thank Professors A. W. Wilkinson and J. F. Soothill for advice and encouragement; and Professor B. E. Clayton for assistance with the biochemical analyses. S.G. was supported by grants from the Joint Research Board of The Hospital for Sick Children and Institute of Child Health, and the Wellcome Research Foundation.

\section{REFERENCES}

Dauncey, M. J., and Widdowson, E. M. (1972). Urine excretion of calcium, magnesium, sodium, and potassium in hard and soft water areas. Lancet, 1, 711.

Ghazali, S., Barratt, T. M., and Williams, D I. (1973). Childhood urolithiasis in Britain. Archives of Disease in Childhood, 48, 291.

Knapp, E. L. (1947). Factors influencing the urinary excretion of calcium. I. In normal persons. fournal of Clinical Investigation, 26, 182.

Lemann, J., Piering, W. F., and Lennon, E. J. (1969). Possible role of carbohydrate-induced calciuria in calcium oxalate kidneystone formation. New England fournal of Medicine, 280, 232.

Macy, I. (1946). Nutrition and Chemical Growth in Childhood, Vol. 2. Original data. Thomas, Springfield, Illinois.

Nordin, B. E. C. (1959). Assessment of calcium excretion from the urinary calcium/creatinine ratio. Lancet, 2, 368.

Paunier, L., Borgeaud, M., and Wyss, M. (1970). Urinary excretion of magnesium and calcium in normal children. Helvetica Paediatrica Acta, 25, 577.

Peacock, M., Hodgkinson, A., and Nordin, B. E. C. (1967). Importance of dietary calcium in the definition of hypercalciuria. British Medical fournal, 3, 469.

Royer, P. (1961). Explorations biologique du métabolisme calcique chez l'enfant. Helvetica Paediatrica Acta, 16, 320.

Wasserman, R. H. (1964). Lactose-stimulated intestinal absorption of calcium. Nature (London), 201, 997.

Widdowson, E. M and McCance, R. A. (1970), Use of random specimens of urine to compare dietary intakes of African and British children. Archives of Disease in Childhood, 45, 547.

Correspondence to Dr. T. M. Barratt, Department of Immunology. Institute of Child Health, 30 Guilford Street, London WC1N 1EH. 